\title{
Fit für den Facharzt: Großes Interesse am Intensivkurs
}

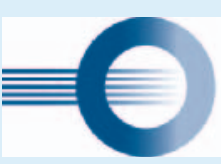

\section{Forum Junge Radiologie}

in der Deutschen Röntgengesellschaft e.V.

Im Herzen von Berlin fanden sich angehende Radiologinnen und Radiologen im Oktober 2019 zum zweiten Fit für den Facharzt-Intensivkurs zusammen. Fünf Tage lang sammelten sie komprimiertes Wissen für die Facharztprüfung. Wie beim ersten Kurs war die Nachfrage groß, weshalb die Teilnehmendenzahl auf 48 erhöht wurde.
Die elf Referentinnen und Referenten, alle mit hoher Expertise in ihrem jeweiligen Fachgebiet ausgestattet, deckten mit ihren Vorträgen das breite Spektrum der Radiologie ab. Denn ob Diagnostik bei Herz und Gefäßen, Neuroradiologie oder Interventionelle Radiologie: Die radiologische Facharztprüfung erfordert ein breites Knowhow. Der Intensivkurs war daher eine hervorragende Gelegenheit, auch die Themen zu vertiefen, die in den Weiterbildungsstationen der Assistenzärztinnen und -ärzte nicht im Vordergrund standen.

\section{Save the Date}

Nach dem erfolgreichen Start der Fit für den Facharzt-Intensivkurse im Jahr 2019 sind bereits Seminare für das Jahr 2020 in Planung. Der erste Kurs wird vom 17. bis 21. Februar $2020 \mathrm{im}$ Hotel Aquino in Berlin-Mitte stattfinden. Ein weiterer Kurs ist für den Herbst geplant.

\section{Mehr Informationen}

Über den Veranstaltungskalender der DRG können Sie sich zu den Fit für den Facharzt-Intensivkursen anmelden: www.drg.de > Veranstaltungen > Veranstaltungskalender 